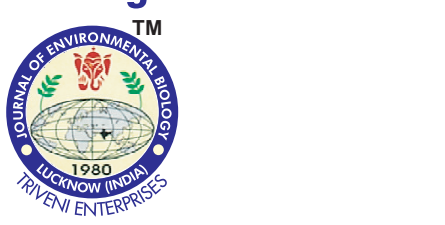

\title{
Defluoridation of water with the help of copper phytoremediated Andrographis paniculata plant biomass
}

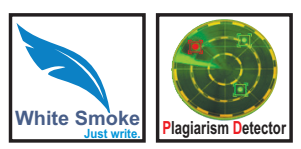

Authors Info

D. Kumar, S.K. Bharti, S. Anand and N. Kumar

Department of Environmental Science, Babasaheb Bhimrao Ambedkar University, Lucknow-226 025, India

*Corresponding Author Email : narendrakumar_lko@yahoo.co.in

Key words

Andrographis paniculata Copper

Defluoridation

Enrichment co-efficient

Phytoremediated biomass

\section{Publication Info}

Paper received : 04.05.2017

Revised received : 13.09 .2017

Re-revised received: 12.02 .2018

Accepted: 16.03.2018

\section{Abstract}

Aim : The present study aimed to defluoridate water with the help of copper phytoremediated A. paniculata plantbiomass.

Methodology : One gram of dry root and shoot of $A$. paniculata (30,60 and 90 days) grown in Cu treated soil $\left(50,100,150 \mathrm{mg} \mathrm{kg}^{-1}\right)$ was digested separately in a solution of $\mathrm{HNO}_{3}: \mathrm{HClO}_{4}(3: 1)$ at $70-80^{\circ} \mathrm{C}$ and was subsequently analyzed on atomic absorption spectrophotometer (AA $240 \mathrm{FS}$, Varian). Biomass of fresh shoot of $A$. paniculata 90 days after sowing (DAS) were collected from the experimental pots (T0, T1, T2 and T3) and washed carefully with double distilled deionized water and sun dried till constant weight. Dried plant biomass samples were ground manually and sieved to obtain powder of below $1.5 \mathrm{~mm}$ diameter and used as a biosorbent. Before applying as a biosorbent, the obtained powdered sample was subjected to acid/alkali treatment. The treated plant material was washed repetitively with double distilled water till clear solution having $\mathrm{pH} 7$ was obtained.

Results : Cu accumulation in roots and shoots after 30, 60 and 90 DAS ranged between $38.19-70.70,57.23-97.38$ and 73.47-184.24 and 25.41-51.23, 26.7155.75 and $43.16-118.03 \mu \mathrm{g} \mathrm{g}^{-1}$ d.wt. respectively. Enrichment coefficient of $\mathrm{Cu}$ in root $\left(\mathrm{EC}_{\text {root }}\right)$ and shoots $\left(\mathrm{EC}_{\text {shoot }}\right)$ at 30,60 and 90 days after treatment ranged between 0.47-0.92, 0.65-1.14, 1.23-2.60 and 0.34-0.51, 0.37-0.53, $0.67-1.48$ respectively. The dried and ground biomass of $A$. paniculata had

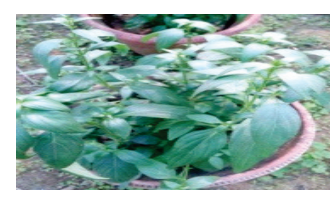

Plant (A. paniculata)

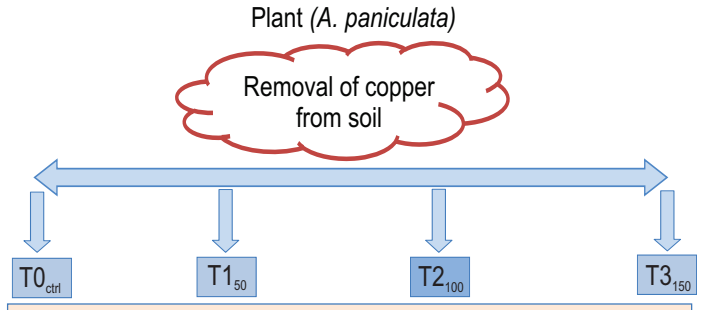

DRY BIOMASS USED FOR DEFLUORIDATION (T0, T1, T2, T3)

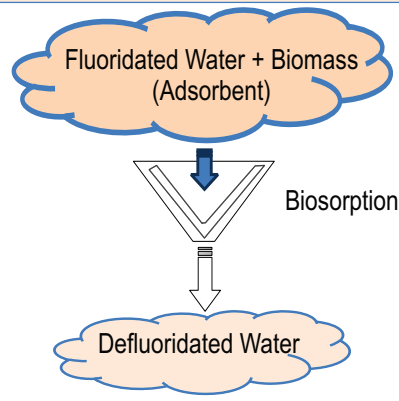

successfully reduced fluoride concentration in water from 5 to $0.784\left(\mathrm{mg} \mathrm{l}^{-1}\right)$ accounting for $84 \%$ removal at an adsorbent dose of $1.5 \mathrm{mg}$, contact time $100 \mathrm{~min}$. and $\mathrm{pH} 3$, respectively.

Interpretation : The correlation coefficient $\left(\mathrm{R}^{2}\right)$ confirmed the suitability of Langmuir and Freundlich isotherms. The $R_{L}$ values indicated favorable adsorption process. Furthermore, Freundlich constant $(n)$ was found to be greater than 1 which also confirmed the favorable adsorption process. 


\section{Introduction}

Rampant industrialization and unorganized anthropogenic activities throughout the world has laid increasing pressure on all components of the environment by releasing enormous quantities of organic as well inorganic contaminants including metal and metalloids. Soil contamination with metals due to several anthropogenic deeds like improper waste management practices, landfill operations, mining, manufacturing and application of sewage sludge etc. has emerged as a major environmental challenge. Agricultural field contamination with metals is not only degrading the quality of soil and foods,but also poses a threat to human health and ecosystem (Mapanda etal., 2005; Singh etal., 2010). Bioavailability of copper $(\mathrm{Cu})$ in soil at optimum concentration is considered as essential micronutrient because it play an important role in plant growth and development (Yruela, 2009), however, its bioavailability even at slightly higher than the optimal level can cause phytotoxicity (Michaud et al., 2008). Anthropogenic deeds e.g. use of pesticide, fungicides and Cu-rich slurries during agricultural practices elevates the level of Cu in soil (Legros et al., 2010; Nagajyoti et al., 2010). Higher concentration of $\mathrm{Cu}$ in soil interferes with the availability of various nutrients by converting ionic species to non-ionic form. At elevated concentration, $\mathrm{Cu}$ can hamper the plant growth by enhancing the generation of reactive oxygen species (ROS) like hydrogen peroxide $\left(\mathrm{H}_{2} \mathrm{O}_{2}\right)$ (Adrees et al., 2015; Habiba et al., 2015; Mei et al., 2015). Various in situ and ex situ remediation approaches like stabilization, solidification, soil washing, vitrification, electrokinetic treatment and phytoremediation are being used for the restoration of metal contaminated land. Among these techniques phytoremediation is a technique that utilizes living plants to reduce, remove, degrade or immobilize the contaminants. This technique emerges as an economical, ecofriendly and most aesthetically acceptable technique (Kumar et al., 2012; Stingu et al., 2012; Kumar et al., 2013; Chayapan et al., 2015). However, proper utilization of biomass generated after phytoremediation is an important concern.

Globally, more than 200 million people are affected with fluorosis in more than twenty nine countries including India (Ayoob et al., 2008). Several techniques are available for the removal of fluoride from water viz., precipitation (Reardon and Wang, 2000), ion exchange, reverse osmosis (Ndiayea et al., 2005), electrodialysis (Kabay et al., 2008) and adsorption (Karthikeyan et al., 2009; Mohan et al., 2012a). Among the available techniques, adsorption had been proven to be effective and economical. Various adsorbents like aluminum based material (Ayoob et al., 2008), algal biosorbent (Mohan et al., 2007), chitosan beads (Liu et al., 2014; Miretzky and Cirelli, 2011), clay soil, carbon based material (Eric et al., 2010; Mohan et al., 2012b), powdered Tinospora cordifolia (Pandey et al., 2012), Echhornia crassipes (Sinha et al., 2003), lime (Islam and Patel, 2006; Gogoi et al., 2015), wheat straw dust, saw dust raw and activated biogass carbon (Yadav et al., 2013) etc. have been applied for the defluoridation. In view of the above, the present study was carried out to assess defluoridation of water with the help of copper phytoremediated Andrographis paniculata plant biomass.

\section{Materials and Methods}

Phytoremediation of $\mathrm{Cu}$; plant materials and treatments : Certified seeds of Andrographis paniculata were procured from the National Seed Disposal Centre, Lucknow, Uttar Pradesh, India. Seed were sown in $30 \mathrm{~cm}$-diameter earthen pots filled with $8.5 \mathrm{Kg}$ (approx) soil. All the pots were watered regularly with ground water to keep the soil moist. Nitrogen $(\mathrm{N})$, phosphorus $(\mathrm{P})$ and potassium (K) @120, 30 and $80 \mathrm{mg} \mathrm{kg}^{-1}$ soil respectively were applied at the time of sowing in the form of urea, single super phosphate and potash. Soil treatments of $\mathrm{Cu}$ were prepared by mixing the appropriate amount of $\mathrm{CuSO}_{4}$ to achieve 50, 100 and $150 \mathrm{mg} \mathrm{Cu} \mathrm{kg}^{-1}$ soil along with control i.e., garden soil. The pots sowed with the seed of $A$. paniculata were kept in the net house of research field station of the Department of Environmental Science, Babasaheb Bhimrao Ambedkar University, Lucknow, India. Seed germination was recorded after six days of sowing and thereafter, plants were thinned to three plants per each pot for further studies. To determine the metal accumulation potential one plant from each pot was uprooted at the interval of 30,60 and 90 days after sowing (DAS). Physico-chemical parameters of experimental soil were examined before initiating the pot experiment.

Estimation of metal content, Enrichment coefficient and Translocation factor : One gram of dried plant sample was digested in a solution of $\mathrm{HNO}_{3}: \mathrm{HClO}_{4}(3: 1)$ at $70-80^{\circ} \mathrm{C}$ for metal estimation. The solution was allowed to evaporate by raising the temperature to $105^{\circ} \mathrm{C}$ until the solution becomes transparent. The final volume was diluted to $25 \mathrm{ml}$ with $0.1 \mathrm{~N} \mathrm{HNO}_{3}$, filtered through Whatman no. 42 filter paper and analyzed on atomic absorption spectrophotometer (AA240 FS, Varian) (Piper, 1942).

Enrichment coefficient (EC) has been determined to derive the degree of heavy metal accumulation in plants following Kisku et al. (2000). Translocation factor (TF) or mobilization ratio of each metal was calculated to determine the translocation of metals from root to shoot of the plant species following Barman et al. (2000).

Defluoridation of water : A $100 \mathrm{mg} \mathrm{l}^{-1}$ stock solution of fluoride was prepared by dissolving $221 \mathrm{mg}$ of anhydrous sodium fluoride of $99.5 \%$ purity in one liter of distilled deionized water from Millipore. Test concentration of $5 \mathrm{mg} \mathrm{l}^{-1}$ was prepared from stock solution following serial dilution technique. Test concentration of 5 $\mathrm{mg} \mathrm{l}^{-1}$ was selected for adsorption experiment since it is considered to be normal fluoride concentration in groundwater. Fresh shoot of $A$. paniculata of 90 days age were collected from the experimental pots (T0, T1, T2 and T3) used for phytoremediation of $\mathrm{Cu}$ from the soil. Plant parts were washed carefully with double distilled deionized water and sun dried for 3 days. Dried plant biomass samples were ground manually with the help of mortar pestle and sieved to obtain powder of below 1.5 $\mathrm{mm}$ diameter. Before applying as biosorbent; the obtained powdered sample was subjected to acid/alkali treatment. Powdered sample of $A$. paniculata $(50 \mathrm{gm})$ was mixed with $500 \mathrm{ml}$ of $1 \mathrm{M} \mathrm{HNO}_{3}$ and heated gently for $20 \mathrm{~min}$. on open flame burner 
then filtered out and washed with double distilled water till the elimination of color. Acid treated sample was subsequently subjected to alkali treatment with $500 \mathrm{ml}$ of $0.5 \mathrm{M} \mathrm{NaOH}$. The treated plant material was washed repetitively with double distilled water till a clear solution of $\mathrm{pH} 7$ was obtained. The obtained powdered biomass was oven dried for $3 \mathrm{hrs}$ at $110^{\circ} \mathrm{C}$ and subsequently cooled in air to room temperature for use.

\section{Results and Discussion}

Physico-chemical properties of experimental soil were investigated prior to seed sowing. Soil was found slightly alkaline with $\mathrm{pH} 7.41, \mathrm{EC} 0.46 \mathrm{ds} \mathrm{m}^{-1}$ and organic carbon $1.38 \%$. Soil was found to be rich in Ca : 3.02 ppm; Fe : 114.32 ppm; Mn: 7.2 ppm; Na: 3.17 ppm; S: 16.58 ppm; and Zn: 2.73ppm. N, P and K content of the soil was found to be $1.39,0.94$ and $3.52 \mathrm{~g} \mathrm{~kg}^{-1}$, respectively. $\mathrm{Ni}, \mathrm{Pb}, \mathrm{Cu}$ and $\mathrm{Cr}$ were present in traces.

Accumulation of $\mathrm{Cu}$ in roots of $A$. paniculata was higher than the shoots in all treatments. Cu accumulation in roots and shoots after 30, 60 and 90 DAS ranged between 38.19-70.70, 57.23-97.38 \& 73.47-184.24; 25.41-51.23, 26.71-55.75 and 43.16-118.03 $\mathrm{ug} \mathrm{g}^{-1} \mathrm{~d}$.wt., respectively (Table 1). Enrichment coefficient (EC) was used to determine the degree of metal accumulation in roots and shoots with respect to metal concentration in growing medium. $\mathrm{EC}_{\text {root }}$ is used as an index for the transfer of metal from soil to plant root, while $\mathrm{EC}_{\text {shoot }}$ determines the degree of transfer of metal from soil to shoot. EC also represents a special feature of the plant to absorb the metals from soil, and subsequently transport them to aerial parts (Zhao et al., 2003; Chen et al., 2005). EC $\mathrm{E}_{\text {root }}$ and $\mathrm{EC}_{\text {shoot }}$ for Cu at 30, 60, 90 days after treatment ranged between $0.47-0.92,0.65-1.14,1.23-$ 2.60 and $0.34-0.51,0.37-0.53,0.67-1.48$, respectively (Fig. 1). A higher value of $\mathrm{EC}_{\text {root }}$ as compared to $\mathrm{EC}_{\text {shoot }}$ indicates that largely the metal was retained in roots.

It has been reported that $E C>1$ indicates the potential of plants to extract and transport metals from the substrate to different plant parts (Wei et al., 2002). Such plant species are considered as hyperaccumulator and can be applied for phytoextraction of metals (Barman et al., 2000; Kumar et al., 2013). Translocation factor (TF) or mobilization ratio determines the translocation of metals from root to shoot and can be used to assess the potential of a plant for phytoremediation. TF for $\mathrm{Cu}$, at 30, 60 and 90 days after treatment ranged between $0.42-0.72,0.44-0.58$ and $0.53-0.64$, respectively. The results revealed that the metal was moderately translocated from root to shoot in A. paniculata (Fig. 1). Several batch experiment were performed to study the adsorption of flouride using $A$. paniculata leaves as biosorbent under different conditions. It was found that the adsorption capacity of biosorbent (powdered leaf sample) was influenced by contact time, $\mathrm{pH}$, initial $\mathrm{F}$ concentration and adsorbent dose.

The influence of contact time on the adsorption efficiency of $\mathrm{F}$ was studied by varrying the contact time from 20 to $120 \mathrm{~min}$. at the adsorbent dose of $5 \mathrm{~g}$ per $25 \mathrm{ml}, \mathrm{pH} 3$ and temparature $28 \pm 2^{\circ} \mathrm{C}$. It was found that initially, the fluoride removal efficieny increased with increase in contact time, however, after $100 \mathrm{~min}$. it became almost stagnant denoting the attainment of adsorption saturation (Fig. 2a). Rapid adsorption at the initial stage may be due to availability of enough active sites for fluoride adsorption, however, with the progress of experiment the active sites became saturated and ultimately, the adsorbent might have been exhausted at the final stages (Killedar and Bhargava, 1993; Chen et al. 2015; Kumari and Khan, 2017; Kofa et al. 2017). Similar findings were reported with various other bisorbents; Pleurotus ostreatus 1804 (Ramanaiah et al., 2007), protonated chitosan beads (Viswanathan et al., 2009), Citrus limonum leaf (Tomar et al., 2014), wheat straw, sawdust and activated bagasse (Yadav et al., 2013).

It is an established fact that the process of biosorption is reliant on the $\mathrm{pH}$, functional groups of the biosorbent and their ionic state (Liu et al., 2014; Yadav et al., 2013). Fluoride removal efficiency was found to decrease with increased pH (Fig. 2b). Biosorbent contains a high amount of polysachharides and some of them are associated with protiens and other biomolecules (Williams and Edyvean, 1997; Panumati et al., 2008). These biomolecules have several functional groups e.g., amine, carboxyl, thiol, sulfhydryl, alcohol, phenol and phosphate. The phenomenon of biosorption depends on the protonation or deprotonation of these functional groups (Ilhami et al., 2005). The ionic form of fluoride in aquous solution and the electric charge of the functional groups of biomolecules (the surface biosorbent) depends on the $\mathrm{pH}$ of the solution. Further, at higher $\mathrm{pH}$, the adsorbent surface becomes negatively charged which leads to electrostatic repulsion between fluoride and

Table 1 : Accumulation of $\mathrm{Cu}\left(\mu \mathrm{g} \mathrm{g}{ }^{-1}\right.$ d.wt.) in different plant parts of $A$. paniculata after 30,60 and 90 days of sowing (DAS)

\begin{tabular}{lllllll}
\hline & \multicolumn{2}{c}{ 30 DAS } & \multicolumn{2}{c}{60 DAS } & \multicolumn{2}{c}{90 DAS } \\
\cline { 2 - 7 } Sample & Root & Shoot & Root & Shoot & Root & Shoot \\
\hline T0 & $5.81 \pm 0.023^{\mathrm{a}}$ & $2.47 \pm 0.005^{\mathrm{a}}$ & $6.91 \pm 0.32^{\mathrm{a}}$ & $2.83 \pm 0.06^{\mathrm{a}}$ & $16.37 \pm 0.56^{\mathrm{a}}$ & $9.31 \pm 0.56^{\mathrm{a}}$ \\
T1 & $38.19 \pm 1.05^{\mathrm{b}}$ & $25.41 \pm 0.93^{\mathrm{b}}$ & $57.23 \pm 1.09^{\mathrm{b}}$ & $26.71 \pm 1.02^{\mathrm{b}}$ & $73.47 \pm 6.2^{\mathrm{b}}$ & $43.16 \pm 2.92^{\mathrm{b}}$ \\
T2 & $53.75 \pm 1.12^{\mathrm{c}}$ & $38.48 \pm 1.43^{\mathrm{c}}$ & $76.06 \pm 2.41^{\mathrm{c}}$ & $44.07 \pm 1.13^{\mathrm{c}}$ & $125.51 \pm 7.01^{\mathrm{c}}$ & $66.87 \pm 3.12^{\mathrm{c}}$ \\
T3 & $70.70 \pm 2.82^{\mathrm{d}}$ & $51.23 \pm 2.03^{\mathrm{d}}$ & $97.38 \pm 4.08^{\mathrm{d}}$ & $55.75 \pm 2.17^{\mathrm{d}}$ & $184.24 \pm 7.42^{\mathrm{d}}$ & $118.03 \pm 6.64^{\mathrm{d}}$ \\
\hline
\end{tabular}

Values represent mean of five replicates \pm SE; Different letters indicates that means are significantly different from each other $(p<0.05)$ 
adsorbent surface resulting in low adsorption capacity (Gajbhiye et al., 2017; Kumari and Khan, 2017).

The effect of adsorbent dose on the fluoride removal from water was examined at pH 6 and contact time of $80 \mathrm{~min}$. The amount of dosage were varied between $0.5 \mathrm{gm}$ to $3 \mathrm{gm}$ per $25 \mathrm{ml}$. The results revealed that upto a certain level, an increase in adsorbent dose resulted in a simultaneous increase in $\mathrm{F}$ removal, probably due to high availibity of surface area and pore volume. Flouride removal efficiency increased from 45.4, 50.8, 49.8 and 51.4 to $79.2,82.14,82.8$ and $83.6 \%$, respectively at $0.5-3 \mathrm{gm}$ dose in different treatments (Fig. $2 \mathrm{c}$ ). All the treatments have followed the similar fluoride removal trend, however, over $1.5 \mathrm{gm}$ adsorbent doses, there were no significant changes in the fluoride removal was noticed; the reason being the overlapping of active sites at a higher dosage, thus decrease in the net available surface area for adsorption (Killender and Bhargava, 1993;
Mondal et al., 2016). Similar results were reported with various other bisorbents viz. protonated chitosan beads (Viswanathan et al., 2009), Citrus limonum leaf (Tomar et al., 2014), Azadirachta indica (Chakrabarthy and Sharma, 2012), wheat straw, sawdust and activated bagasse (Yadav et al., 2013).

The effect of initial fluoride concentration on the removal efficiency was investigated by adding the fixed amount of adsorbent dose $(2 \mathrm{gm})$ into different concentrations of fluoride solution $\left(2.5,5,7.5,10,12.5\right.$ and $\left.15 \mathrm{mg} \mathrm{l}^{-1}\right)$ for $100 \mathrm{~min}$. The results demonstrated that fluoride removal efficiency decreased with increase in the initial fluoride concentration (Fig. 2d). The deacrease in fluoride removal efficiency indicates that the capacity of adsorbent gets exhausted abruptly on increasing the initial fluoride concentration probably due to instant saturation of active adsorbent sites at higher fluoride concentration (Mondal et al., 2016). Similar trends have been reported by several authors

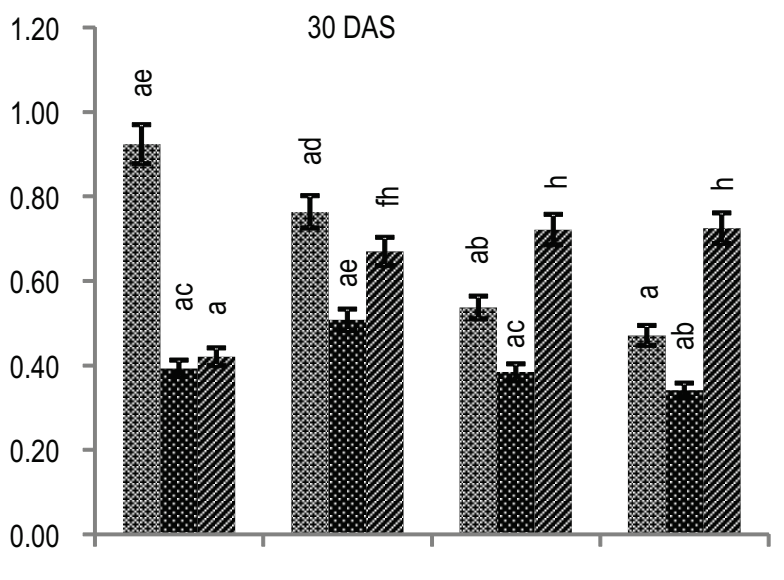

T0
$\mathrm{T} 1$
T2

T3

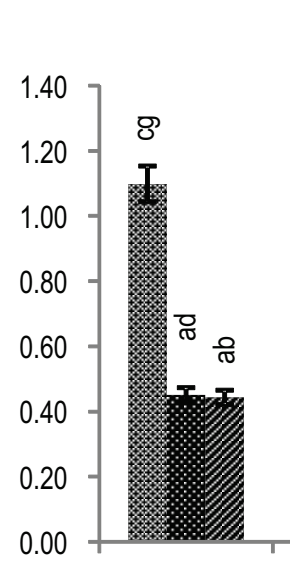

T0
60 DAS

ర্

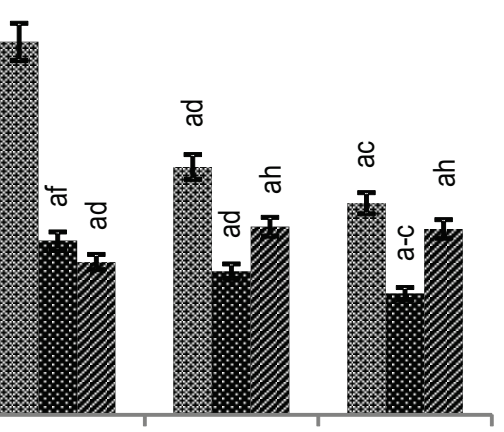

$\mathrm{T} 1$

$\mathrm{T} 2$

T3

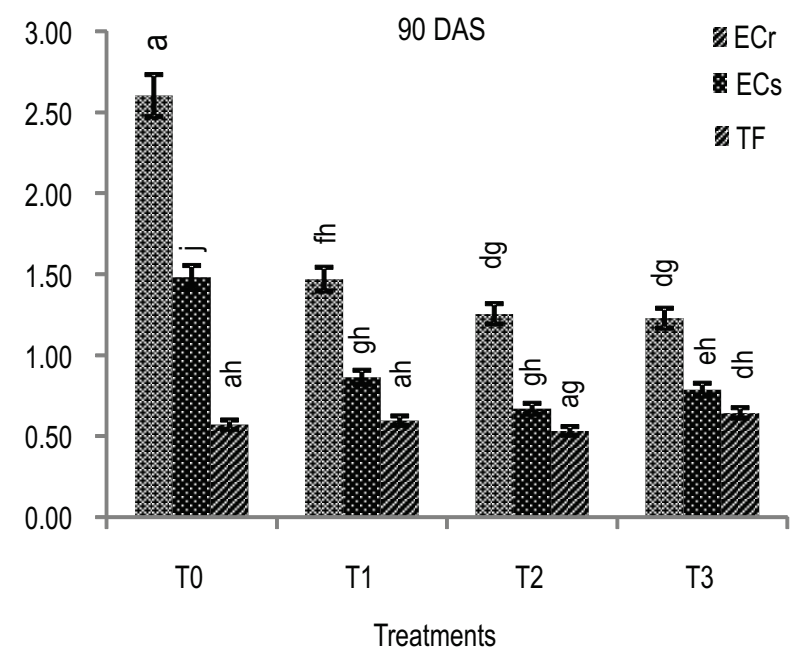

Fig. 1 : Accumulation of $\mathrm{Cu}\left(\mu \mathrm{g} \mathrm{g}^{-1} \mathrm{~d}\right.$. wt.) in different plant parts of $A$. paniculata after 30,60 and 90 days of sowing (DAS). ECr- Enrichment Co efficient of root, ECs-Enrichment Coefficient of shoot, TF-Translocation Factor 

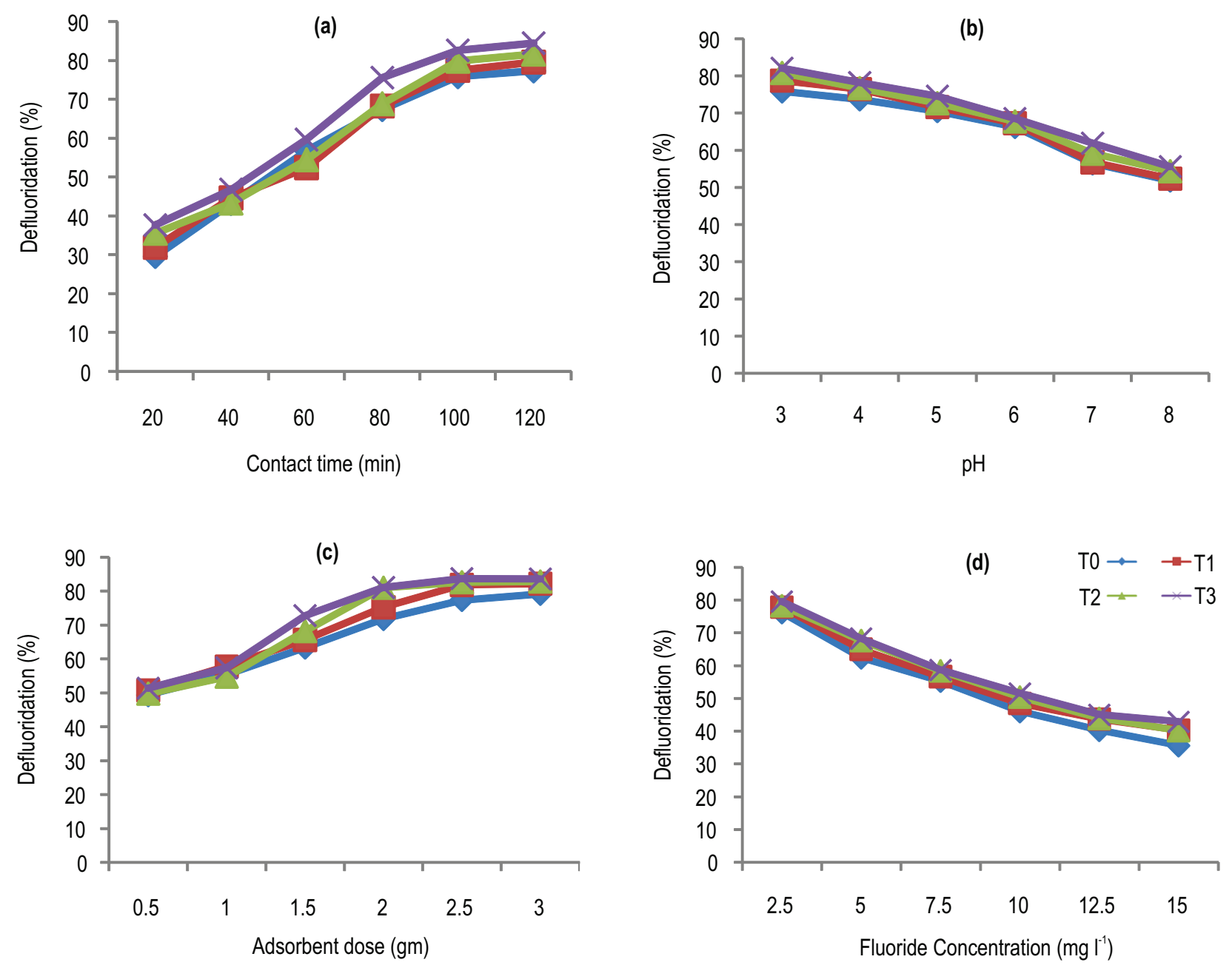

Fig. 2 : Effect of (a) contact time, (b) pH, (c) adsorbent dose and (d) initial fluoride concentration on the pecent fluoride removal from water by Cu phytoremediated $A$. paniculata plant biomass
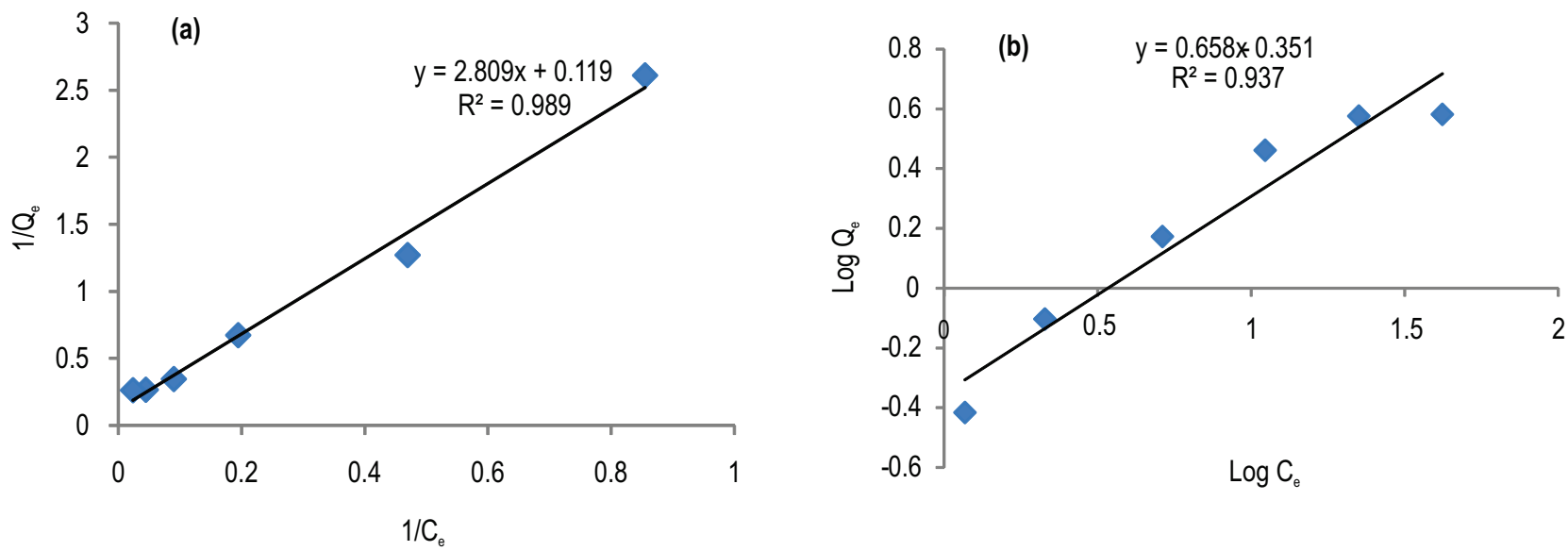

Fig. 3 : Linear model of Langmuir isotherm (a) and Freundlich isotherm (b) for adsorption of fluoride at $1 \mathrm{~g} 10 \mathrm{ml}^{-1}$ volume, $\mathrm{pH} 3$, temp $30^{\circ} \mathrm{C}$, contact time of $120 \mathrm{~min}$ and different initial concentration of adsorbent 
for fluoride removal from water using protonated chitosan beads (Viswanathan et al., 2009), algal biomass (Mohan et al., 2007), wheat straw, sawdust, activated bagasse of sugarcane (Yadav et al., 2013), Azadirachta indica (Chakrabarty and Sarma, 2012) and lemon leaf (Tomar et al., 2014).

Langmuir and Freundlich isotherms are considered as essential models for understanding the adsorption process. The Langmuir isotherm is based on saturated molecular layer (monolayer) adsorption on the active sites of the adsorbate, while Freundlich isotherm is based on adsorption on a heterogeneous surface and a multilayer adsorption with an energetic non uniform distribution (Liu et al., 2011; Cai etal., 2015). A plot of $1 / Q_{e}$ against $1 / C_{e}$ shows a straight line which indicates that the adsorption process followed the Langmuir isotherm (Fig. 3a). Further, a plot of $L \circ g Q_{e}$ against $L \circ g C_{e}$ showed a linearity of Freundlich isotherm plot which confirms the applicability of Freundlich model for defluoridation at different initial concentrations (Fig. 3b).

The correlation coefficient $\left(R^{2}\right)$ of Langmuir and Freundlich isotherms was greater than 0.93 indicating that both the models could explain the adsorption of fluoride. Maximum adsorption capacity $\left(Q_{\max }\right)$ from Langmuir isotherm model was 3.8 $\mathrm{mg} \mathrm{g}^{-1}$ which was higher than wheat straw, sawdust, and activated bagasse $\left(1.93,1.73\right.$ and $\left.1.15 \mathrm{mg} \mathrm{g}^{-1}\right)$ as reported by Yadav et al., (2013). The values of $R L$ ranged between of 0.118-0.681, indicating favorable adsorption process. Furthermore, Freundlich constant ' $n$ ' ( $n=1.51$ ) was found to be greater than 1 which also confirms the favorable adsorption process (Zhang and Jia, 2016; Ghada et al., 2018). The present study concludes that $A$. paniculata plant can be used as a moderate phytoremediator of $\mathrm{Cu}$, however, use of $A$. paniculata biomass for removal of fluoride from contaminated water is an added advantage to the remediation process.

\section{Acknowledgments}

Authors would like to thank the Head, Department of Environmental Science, BBAU, Lucknow, India for providing infrastructural underpin. Authors are also thankful to the University Grant Commission, New Delhi, India for the financial assistance extended to Mr. Dhananjay Kumar and Mr. Sushil Kumar Bharti in the form of UGC-JRF fellowship for doctoral research.

\section{References}

Adrees, M., S. Ali, M. Rizwan, M. Ibrahim, F. Abbas, M. Farid, M. Zia-urRehman, M.K. Irshad and S.A. Bharwana : The effect of excess copper on growth and physiology of important food crops : A review. Environ. Sci. Pollut. Res., http:// dx.doi.org/ 10.1007/ s113 56-015-4496-5(2015).

Ayoob, S., A.K. Gupta and T.B. Venugopal : A conceptual overview on sustainable technologies for the defluoridation of drinking water. Crit. Rev. Environ. Sci. Technol., 38, 401-470 (2008).

Barman, S.C., R.K. Sahu, S.K. Bhargava and C. Chaterjee : Distribution of heavy metals in Wheat, Mustard and weed grown in field irrigated with industrial effluents. Bull. Environ. Contam. Toxicol., 64, 489-496 (2000).
Cai, H., G. Chena, C. Penga, Z. Zhanga, Y. Donga, G. Shanga, X. Zhua, $X$. Gaob and X. Wan : Removal of fluoride from drinking water using tea waste loaded with Al/Fe oxides : A novel, safe and efficient biosorbent. Appl. Surf. Sci., 328, 34-44 (2015).

Chakrabarty, S. and H.P. Sarma : Defluoridation of contaminated drinking water using neem charcoal adsorbent : Kinetics and equilibrium studies. Int. J. Chem. Tech. Res., 4, 511-516 (2012).

Chayapam, P., M. Kruatrachue, M. Meetam and P. Pokethiyook: Phytoremediation potential of $\mathrm{Cd}$ and $\mathrm{Zn}$ by wetland plants, Colocasia esculenta L. Schott., Cyperus malaccensis Lam., and Typha angustifolia L. grown in hydroponics. J. Environ. Biol., 36, 1179-1183(2015).

Chen, S.B., Y.G. Zhu and Q.H. Hu : Soil to plant transfer of ${ }^{238} \mathrm{U},{ }^{226} \mathrm{Ra}$ and 232Th on $U$ mining-impacted soil from Southeastern China. J. Environ. Radioact., 82, 223-236(2005).

Chen, G., C. Peng, J. Fang, Y. Dong, X. Zhu and H. Cai: Biosorption of fluoride from drinking water using spent mushroom compost biochar coated with aluminum hydroxide. Desalin. Water Treat., DOI: 10.1080/19443994.2015.1049959 (2015).

Eric, T.K., A. Véronique, C.P. Nanseu-Njiki, A. Nathalie, N. Emmanuel and D. Andre: Preparation and characterization of charcoals that contain dispersed aluminum oxide as adsorbents for removal of fluoride from drinking water. Carbon, 48, 333-343 (2010).

Gajbhiye, A., K, Kulkarni and A. D. Kulkarni : Calcium ion impregnated on water hyacinth for defluoridation of water. Int. J. Sci. Res. Manage., 5, 5692-5699 (2017).

Ghada, F.E., M.E. Manal and A. A. Mohamed: Adsorption isotherms and kinetic studies for the defluoridation from aqueous solution using eco-friendly raw marine green algae, Ulvalactuca. Environ. Monit. Assess., 190, 1-14 (2018).

Gogoi, S., S.K. Nath, S. Bordoloi and R.K. Dutta : Fluoride removal from groundwater by limestone treatment in presence of phosphoric acid. J. Environ. Manag., 152, 132-139 (2015).

Habiba, U., S. Ali, M. Farid, M.B. Shakoor, M. Rizwan, M. Ibrahim, G.H. Abbasi, T. Hayat and B. Ali : EDTA enhanced plant growth, antioxidant defence system and phytoextraction of copper by Brassicanapus L. Environ. Sci. Pollut. Res., 22, 1534-1544 (2015).

Ilhami, T., B. Gulay, Y. Emine and B. Gokben : Equilibrium and kinetic studies on biosorption of $\mathrm{Hg}(\mathrm{II}), \mathrm{Cd}$ (II) and $\mathrm{Pb}$ (II) ions onto micro algae Chlamydomonas reinhardtii. J. Environ. Manag., 77, 85-92 (2005).

Islam, M. and P.K. Patel : Evaluation of removal efficiency of fluoride from aqueous solution using quick lime. J. Hazard. Mat., 143, 303-310 (2006).

Kabay, N., O. Arar, S. Samatya, U. Yuksel and M.Yuksel: Separation of fluoride from aqueous solution by electrodialysis: effect of process parameters and other ionic species. J. Hazard. Mater., 153, 107$113(2008)$.

Karthikeyan, M., K.K. Satheesh and K.P. Elango : Conducting polymer/alumina composites as viable adsorbents for the removal of fluoride ions from aqueous solution. J. Fluor. Chem., 130, 894-901 (2009).

Killedar, D.J. and D.S. Bhargava: Effects of stirring rate and temperature on fluoride removal by fishbone charcoal. Ind. J. Environ. Hlth., 35, 81-87 (1993).

Kisku, G.C., S.C. Barman and S.K. Bhargava : Contamination of soil and plants with potentially toxic elements irrigated with mixed industrial effluent and its impact on the environment. Water. Air. Soil. Poll., 120, 121-137 (2000).

Kumar, N., K. Bauddh, S.C. Barman, N. Dwivedi and D.P. Singh : Accumulation of metals in selected macrophytes grown in mixture of drain water and tannery effluent and their phytoremediation potential. J. Environ. Biol., 33, 923-927 (2012). 
Kumar, N., K. Bauddha, S. Kumar, N. Dwivedi, D.P. Singh and S.C. Barman: Accumulation of metals in weed species grown on the soil contaminated with industrial waste and their phytoremediation potential. Ecol. Eng., 61, 491-495(2013).

Kumari, S. and K. Supriya: Defuoridation technology for drinking water and tea by green synthesized $\mathrm{Fe}_{3} \mathrm{O}_{4} / \mathrm{Al}_{2} \mathrm{O}_{3}$ nanoparticles coated polyurethane foams for rural communities. Nature Scientific Reports (2017). doi: 10.1038/s41598-017-08594-7.

Kofa, G. P., V. H. Gomdje, C. Telegang and S. N. Koungou. Removal of fluoride from water by adsorption onto fired clay pots: Kinetics and equilibrium studies. J. Appl. Chem. DOI:.org/ 10.1155/ 2017 / 6254683 (2017).

Legros, S., P. Chaurand, J. Rose, A. Masion, V. Briois, J.H. Ferrasse, H.S. Macary, J.Y. Bottero and E. Doelsch: Investigation of copper speciation in pig slurry by a multi technique approach. Environ. Sci. Technol., 44, 6926-6932 (2010).

Liu, J., W. Li, Y. Liu, Q. Zeng and S. Hong : Titanium (IV) hydrate based on chitosan template for defluoridation from aqueous solution. Appl. Surf. Sci., 293, 46-54 (2014).

Liu, J.S., J.Y. Si, Q. Zhang, Z.H. Zheng, C.L. Han and G.Q. Shao : Preparation of negatively charged hybrid adsorbents and their applications for $\mathrm{Pb}^{2+}$ removal. Ind. Eng. Chem. Res., 50, 86458657 (2011).

Mapanda, F., E.N. Mangwayana, J. Nyamangara and K.E. Giller : The effect of long-term irrigation using waste water on heavy metal contents of soils under vegetables in Harare, Zimbabwe. Agri. Ecosys. Environ.,107, 151-165(2005).

Mei, L., M.K. Daud, N. Ullah, S.Ali, M. Khan, Z. Malik and S.J. Zhu : Pretreatment with salicylic acid and ascorbic acid significantly mitigate oxidative stress induced by copper in cotton genotypes. Environ. Sci. Pollut. Res., http : //dx.doi.org/ 10.1007/ s113561015 (2015)

Michaud, A.M., C. Chappellaz and P. Hinsinger : Copper phytotoxicity affects root elongation and iron nutrition in durum wheat (Triticumt urgidum durum L.). Plant Soil, 310, 151-165 (2008).

Miretzky, P. and A.F. Cirelli: Fluoride removal from water by chitosan derivatives and composites: A review, J. Fluor. Chem., 132, 231240 (2011).

Mohan, D., R. Sharma, V.K. Singh, P. Steele and C.U. Pittman: Fluoride removal from water using bio-char, a green waste, low-cost adsorbent: equilibrium uptake and sorption dynamics modeling. Ind. Eng. Chem. Res., 51, 900-914 (2012b).

Mohan, D., R. Sharma, V.K. Singh, P. Steele and C.U. Pittman : Modeling and evaluation of chromium remediation from water using low cost bio-char, a green adsorbent. J. Hazard. Mater., 188, 319-333 (2012a).

Mohan, S.V., S.V. Ramanaiah, B. Rajkumar and P.N. Sarma : Removal of fluoride from aqueous phase by biosorption onto algal biosorbent Spirogyra sp.-IO2 : sorption mechanism elucidation. J. Hazard. Mater.,141, 465-474 (2007).

Mondal, N.K., R. Bhaumik and J.K. Datta: Fluoride Adsorption by calcium carbonate, activated alumina and activated sugarcane ash. Environ. Process., 3,195-216 (2016).
Nagajyoti, P.C., K.D. Lee and T.V.M. Sreekanth : Heavy metals, occurrence and toxicity for plants : A review. Environ. Chem. Lett., 8, 199-216 (2010).

Ndiaye, P.I., P. Moulin, L. Dominguez, J.C. Millet and F. Charbit : Removal of fluoride from electronic industrial effluent by RO membrane separation. Desalinization, 173, 25-32 (2005).

Pandey, P.K., M. Pandey and R. Sharma: Defluoridation of water by a biomass: Tinospora cordifolia. J. Environ. Prot., 3, 610-616 (2012).

Panumati, S., K. Chudecha, P. Vankhaew, V. Choolert, L. Chuenchom, W. Innajittara and O. Sirichote : Adsorption of phenol from diluted aqueous solution by activated carbons obtained from bagasse, oil palm shell and pericarp of rubber fruit. J. Sci. Technol., 30, 185-189 (2008).

Piper, C.S.: Soil and PlantAnalysis. Univ. of Adelaide, Adelaide, Australia (1942).

Ramanaiah, S.V., S.V. Mohan and P.N. Sarma: Adsorptive removal of fluoride from aqueous phase using waste fungus (Pleurotus ostreatus 1804) biosorbent : Kinetics evaluation, Ecol. Eng., 31, 47-56 (2007)

Reardon, E.J. and Y. Wang: Limestone reactor for fluoride removal from waste water. Environ. Sci. Technol., 34, 3247-3253 (2000).

Singh, R., D.P. Singh, N. Kumar, S.K. Bhargava and S.C. Barman: Accumulation and transcolation of heavy metals in soil and plants from fly ash contamination. J. Environ. Biol., 3, 421-430 (2010).

Sinha, S., K. Pandey, D. Mohan and K.P. Singh: Removal of fluoride from aqueous solutions by Eichhornia crassipes biomass and its carbonized form. Ind. Eng. Chem. Res., 42, 6911-6918 (2003).

Stingu, A., I. Volf, V.I. Popa and I. Gostin : New approaches concerning the utilization of natural amendments in cadmium phytoremediation. Ind. Crop. Prod., 35, 53-60 (2012).

Tomar, V., S. Prasad and D. Kumar : Adsorptive removal of fluoride from aqueous media using Citrus limonum (lemon) leaf. Microchem. J., 112, 97-103 (2014).

Viswanathan, N., C.S. Sundaram and S. Meenakshi : Removal of fluoride from aqueous solution using protonated chitosan beads. J. Hazard. Mater., 161, 423-430 (2009).

Wei, C.Y., T.B. Chen and Z.C. Huang: Cretan Bake (Pteriscretica L.): An arsenic accumulating plant. Acta Ecologica Sinica, 22, 777-782 (2002).

Williams, C.J. and R.G.J. Edyvean: lon exchange in nickel biosorption by seaweed materials. Biotechnol. Prog.,13, 424-428 (1997).

Yadav, A.K., R. Abbassi, A. Gupta and M. Dadashzadeh : Removal of fluoride from aqueous solution and ground water by wheat straw, sawdust and activated bagasse carbon of sugarcane. Ecol. Eng., 52, 211-218(2013).

Yruela, I.: Copper in plants : acquisition, transport and interactions. Funct. Plant. Biol., 36, 409-430 (2009).

Zhang, Y.X. and Y. Jia : Fluoride adsorption onto amorphous aluminum hydroxide: Roles of the surface acetate anions. J. Coll. Inter. Sci., 483, 295-306 (2016).

Zhao, F.J., E. Lombi and S.P. McGrath : Assessing the potential for zinc and cadmium phytoremediation with the hyperaccumulator Thlaspicaerulescens. Plant Soil, 249, 37-43 (2003). 